\title{
A VIDA SEXUAL APÓS O PARTO*
}

Sandra Cristina Poerner Scalco ${ }^{1}$; Walter Oliveira ${ }^{2}$

\section{LOVE AND SEX AFTER CHILDBIRTH}

Resumo: "A Vida Sexual após o Parto" é uma pesquisa fenomenológica, com substrato filosófico sistêmico, e existencialista, que oferece uma reflexão sobre a sexualidade após o parto. Esclarece que este momento expressa a vivência diária, mitos e valores, de casais que passaram pela experiência de ter um filho e demonstra como o sexo pode sobreviver, principalmente se estiver relacionado a um processo amplo que envolve as relaçóes afetivosexuais entre seres humanos, preservando assim a qualidade de vida sexual de ambos.

Palavras-chave: Vida sexual pós-parto; sexualidade; fenomenologia; disfunção sexual.

Abstract: "Postpartum sex life" is a phenomenological research with a systemic philosophical underpinning. There are many doubts permeating the postpartum practice of sex and exertion of sexuality. It would be crucial that professionals who deal with the topic sexuality be prepared to elucidate and provide advise on this issue. The present study provides a consideration on postpartum sexuality, elucidating that this concept reflects daily life, beliefs, myths and values that are related a broad process involving the sexual-affective relations among human beings.

Keywords: Postpartum sex life; sexuality; phenomenological research; sexual dysfunction.

* 0 artigo enviado foi extraído de dissertação defendida no mestrado de Saúde Coletiva, na ULBRA, na área de Saúde mental; linha de pesquisa: Vivências Humanas, Familia e Comunidade. Com orientação do Prof. Dr. Walter Oliveira,

1 Universidade Luterana - ULBRA. e-mail: sandrascalco@yahoo.com.br

2 Doutor em Psiquiatria, Professor na UFSC. e-mail: wjolive@terra.com.br 


\section{Introdução}

A pesquisa buscou a compreensão da questão: "Que significado passou a ter a vida sexual após o parto?”. Sabe-se que a sexualidade humana além de sua função natural - a reprodução - também traduz uma busca psicológica. É linguagem própria do homem na qual é possível comunicar-se com o outro, expressão de intimidade e de desejo, podendo ir além da genitalidade, como um construto simbólico cultural. As dificuldades sexuais que surgem ou retornam no pós-parto, gerando a inadequação sexual são definidas por Cavalcanti (1997) como insatisfação com a própria sexualidade ou do parceiro, de acordo com o padrão normativo intra e interpessoal. Há que se considerar que no período puerperal, dada a recuperação psico-fisiológica intrínseca, inclusive do ponto de vista do casal as mudanças na rotina de vida, a variação emocional, a lactação, as alteraçōes hormonais e outros fatores são inerentes a esse período de readaptação. Para Vitiello (2000), a fase puerperal é o momento da vida onde podem aflorar sentimentos de repressão e incompreensão exacerbando-se a percepção negativa da sexualidade que a nossa cultura propaga.

Na retomada da intimidade do casal, pós-parto, a identidade de ambos passa por um processo de ressignificação com a aquisição de novos papéis. A maturidade em sexualidade, nesse contexto, se traduz pela capacidade de satisfazer a si e ao outro, gerando qualidade na relação. O melhor insight do rearranjo sexual, no contexto familiar, resgata lacunas; entendendo-se o sexo "maduro" como aquele onde o indivíduo é capaz de perder-se no outro e reencontrarse depois acrescido, somado. (CARIDADE, 1997).

\section{Área temática e objetivos}

A área temática é: "Compreensão das implicações no processo de retomada da vida sexual do casal, após o parto”.

O estudo teve como objetivos compreender a relação do casal durante o processo de retomada da vida sexual após o parto quanto: a ressignificação do vínculo, aos sentimentos vivenciados em relação à retomada, às vivências mais significativas, à configuração de novos papéis, à reestruturação na identidade de ambos e implicações na sexualidade e às disfunções e /ou às inadequações sexuais. 


\section{Metodologia}

Na pesquisa foi eleita a fenomenologia proposta por Martins e Bicudo (1989), que amplia a compreensão do fenômeno indagado, valendo-se das experiências dos próprios indivíduos que o experienciam e dos significados que estes indivíduos lhe atribuem. A intenção é compreender ao invés de explicar. Por esta razão, é de caráter qualitativo com fundamentação teórica em uma perspectiva fenomenológica, com base em autores existencialistas como: Merleau-Ponty (1975) e Heidegger (1988).

A fenomenologia contemporânea é um movimento da filosofia que surgiu com Husserl, no final do século XIX e início do século XX, durante a crise do subjetivismo e do irracionalismo. Seu principal objetivo é a investigação do vivido descrevendo os fenômenos como são experenciados, livres de conceitos e teorizaçōes (HENNEMANN, 1990). A fenomenologia opōe-se ao cientismo, com sua pretensa ênfase na objetividade e na matematização da realidade. “[...] Consiste na atividade científica, no melhor sentido da palavra, sem ser, ao mesmo tempo, esmagada pelas pressuposições da ciência e sofrer suas limitações." (ZILLES, 1986, p.193).

\section{Campo e ação}

O trabalho envolveu 5 casais heterossexuais ( 5 homens e 5 mulheres), convivendo maritalmente há mais de três anos e tivessem tido seu primeiro filho(a), num período retrospectivo de seis à doze meses, com ou sem queixa na relação sexual. A idade dos casais variou de 21 a 42 anos, o tempo disponível utilizado para entrevista era livre, e teve como variabilidade, 70 a 190 minutos. A distribuição se deu aos pares, exemplo: - casal 1 e 2, 3 e 4 e assim sucessivamente, então de 1 a 9, os números ímpares, correspondem ao sexo feminino, e números pares, ao sexo masculino. Com relação às inadequações: no casal 1 e 2, a entrevistada 1 tinha queixa de anorgasmia primária e diminuição de desejo enquanto o marido, tinha ejaculação precoce. No casal 3-4, havia por parte da entrevistada, anorgasmia situacional, e o parceiro desejo sexual hipoativo. Já os casais 5-6, 7-8 tiveram uma boa readaptação e não tinham queixas sexuais. Enquanto que no casal 9-10, existia uma queixa de dispareunia e diminuição de desejo após o parto, seu parceiro não tinha queixas. O início das relaçôes sexuais: variou de 1 a 5 meses. As categorias encontradas foram: a ressignificação do vínculo de casal, a retomada da vida sexual após o parto, as vivências significativas na configuração de novos papéis, a reestruturação da identidade, tipos de disfunções sexuais ou inadequações. 
As entrevistas foram analisadas pelos 4 passos do método fenomenológico descritos por Giorgi (1985) enriquecidas pela contribuição de um quinto passo por Comiotto (1992). A seguir, descritos: 1 - O sentido do todo: Equivale à etapa da "descrição do fenômeno" proposto por Merleau-Ponty (1975). 2 - Unidades de significado: a redução fenomenológica é resultado de um conjunto de asserçōes significativas para o pesquisador. 3 - Transformação das unidades de significados: a identificação das unidades de significados. 4 - Síntese do todo: unidades com mesmo sentido, resumidas em um texto objetivo. 5 - Dimensões fenomenológicas: Comiotto (1992) propõem uma redução da síntese do todo, para apreensão das essências do fenômeno.

Serviram também de base, as idéias de: 1 - Martin Buber (1974) sobre o homem que é um ser relacional capaz de múltiplas relaçôes, expressa basicamente em atitudes definidas com base nas palavras Eu-Tu e Eu-Isso. A atitude Eu-Tu caracteriza-se pela responsabilidade, reciprocidade, totalidade, espontaneidade, constituindo-se num modo de relacionamento que revela o significado de existência, pois define o mundo do relacionamento existencial. A atitude Eu-Isso se caracteriza pela forma superficial e impessoal de relação onde não há envolvimento e compromisso com o outro. 2 - Foucault (1982) que cita a reversibilidade bem como a polivalência que conferem à analogia um campo universal de aplicação - o que sedimenta um estudo fenomenológico de população reduzida; pois as figuras do mundo podem se aproximar.

\section{Apresentação dos resultados e discussões}

A "Vida sexual após o parto", demonstrou duas essências, comuns na fala de todos: "O vínculo de casal na ressignificação do sexo" e "A retomada da vida sexual", as quais são inclusas na dimensão chamada "Vida Sexual"; surgindo da análise dessas os questionamentos : - "Por que estamos juntos?", “Que significado tem o sexo agora?" e "Como foi voltar a fazer sexo?”.

A partir deste momento, um segundo plano perpassa as seguintes essências: "Vivências do casal", "Reestruturação da identidade" e possíveis "Disfunçôes", do qual emerge a questão: - "Como é que eu faço?[...]”.A seguir, num momento de identificação, distribuição de papéis e eventuais conflitos: “Quem sou eu agora?”. Por fim, havendo problemas nas etapas anteriores, a possibilidade de identificação de um desajuste ou queixa sexual: - "O que houve de errado?". 
A partir das essências, chegou-se a um roteiro de perguntas (extrato das essências), a ser utilizado para guiar ao que se propõem às considerações finais, através de questionamentos para elaboração de atendimento preventivo, no entendimento da sexualidade no pós-parto.

\section{A VOZ DOS INFORMANTES}

\section{I - A VIDA SEXUAL}

\section{Ia - A ressignificação do sexo e o vínculo de casal}

"[...] Acho que no momento em que tu vais para a cama, faz amor, fica com uma pessoa, tu já és íntimo dela, mas agora eu relaciono isso a um companheirismo maior [...]. Não que nós não fôssemos uma família, mas agora somos uma família completa [...]” (entrevistada 5). "[...] As emoçōes, o casamento, a vida, todo esse conjunto é bem melhor, e isso cria, laços, só tende a crescer, e na relação também, no sexo, porque é um complemento da vida." (entrevistado 6).

Buber (1974) e Moreno (1974) comentam que existe uma unicidade dos seres humanos, por meio das essências, quando se está em um relacionamento fluente, não há obstrução da comunicação luminosa, essa luz representa a alma em sua essência, a parte inominada do homem. O entendimento de amor e sexo vinculados ao discurso da troca, da intimidade que se revela acrescentando sentimentos de amadurecimento.

\section{$\mathrm{Ib}-\mathrm{A}$ retomada sexual}

“[...] A primeira vez que a gente tentou depois de mais ou menos 40 dias após o parto, doeu demais, mesmo usando lubrificante, doeu tanto que acho que naquele dia a gente nem conseguiu, como se eu estivesse sendo rasgada, chorei, fiquei com medo, e depois disso a gente demorou para tentar de novo (entrevistada 1)". "Eu acho que desde que ela (filha) nasceu, levou uns 2 ou 3 meses que eu me lembre, para que eu estivesse mais ou menos com vontade, agora ele, não queria tocar no meu seio, o seio era de "Alice", então isso fez com que ele demorasse um pouco mais a me procurar [...] "o seio é dela", "o leite é dela”, até ele conseguir vencer isso daí [...]" (entrevistada 3). “[...] Quando eu comecei, ela não tinha prazer, então com muito carinho a gente conseguiu. É difícil, tem que ter compreensão na relação, se for egoísta se rala, se a gente se gosta, vive junto, se no primeiro problema desiste, não 
consegue nada, não é só querer, tem que estimular, vai fazendo o que ela quer da maneira que tu quer também, isso aí tu tens poder de fazer [...]" (entrevistado 8).

No contexto acima, de retomada da vida sexual após o parto, têm-se as vozes de diferentes casais, uns numa relação que Buber (1974) classificaria como EU-ISSO, com maior dificuldade na recíproca do afeto e na sua manutenção, agora com a vivência significativa da existência de um terceiro indivíduo (o filho). Enquanto que outros num resgate, com intensificação da vida sexual conjugal, onde fica explícito o discurso EU-TU, na valorização do outro e no entendimento da totalidade desta nova fase.

\section{II - VIVÊNCIAS DO CASAL E NOVOS PAPÉIS}

\section{A disposição de horários}

“[...] No início, houve aquela parada, no começo é meio difícil, conversar de novo, ter aquele clima de novo, é bem diferente. É que eu tenho um horário de trabalho muito difícil, e às vezes um tem que puxar o outro para a gente se manter [...]" (entrevistado 2).

\section{As cólicas}

“[...] Ela teve cólica uns três meses, aí era aquela coisa de ter que se revezar à noite, às vezes dava um cansaço, mas também não é tão ruim quanto falavam [...]" (entrevistado 10).

\section{O quarto do bebê}

“[...] Até o oitavo mês ele (filho) dormia entre nós, sempre, para mim era tão bom dormir abraçadinha nele, mas as pessoas pressionavam: - tá errado! - Aí para acabar com essa polêmica passei a botar o filho no quarto dele, ah! [...] chorei umas duas noites, não sei se de braba ou de saudades." (1)

\section{Mudanças de hábitos}

“[... Ele não é nem louco de chegar às 3:00 da manhã, e me convidar para ter um relacionamento íntimo [...]” (1).“[...] Na verdade, fica mais para ela, mas eu quando posso, troco fraldas, se eu posso dar uma comidinha, eu dou, passeio, saio com ele, mas no mais é ela!" (2). 


\section{A amamentação}

“[...] Às vezes ele estava bem, mamando, se eu pegava no telefone, para dizer para alguém: - Eu tô viva!, ele começava a chorar, gritar [...] eu ficava furiosa, porque o único minuto que eu tinha para falar com alguém, ele não deixava [...]"(1).

\section{A família}

“[...] A mãe morava muito longe... me deu uma carência tão profunda, meu Deus! Eu necessitava ser amada, eu perguntava todo dia para o meu marido, tu me amas? - Eu me sentia obrigada a cuidar de alguém, enquanto era eu que estava precisando de cuidado" (1) “[...] Quando a gente é mãe, a gente entende o que a mãe da gente passou, passa a dar mais valor...” (5).

\section{O que mudou... em análise}

"A gente mudou muito um com o outro, ele era mais carinhoso comigo, uma coisa que me deixa assim, é eu estar fazendo um serviço, aí ele vem, me abraça, me beija...não quero que fique me agarrando quando eu tenho serviço para fazer!” (3).

Segundo Hudson (1995), para uma família ou um casal, ter um senso de estabilidade, é vital ter horários e atividades rituais de alguma forma, protegidos por essa continuidade. $\mathrm{O}$ forte impacto dos rituais de continuidade foi destacado também, pelas pesquisas realizadas por Jacobs e Wolin (1989) ao defenderem que estes proporcionam uma ligação que ajuda os casais e as famílias a sobreviver e a permanecem unidos nas épocas difíceis.

\section{III - REESTRUTURAÇÃO DA IDENTIDADE SEXUAL}

Money (1986) estudioso da identidade e dos papéis sexuais, ressalta que sempre haverá diferenças entre os sexos em termos de comportamento. Não é fácil distinguir no psicológico as conseqüências imutáveis dos fatores biológicos, devido às constelaçôes culturais.

“[...] Antes, nós dormíamos juntos sempre. Antes, se um estava fazendo uma coisa, o outro esperava, para a gente ir dormir junto" (entrevistada 3). "Ah! Eu acho que mudou... eu não vejo nada em comum com a pessoa que eu era, acho que amadureci tanto, estou levando a vida mais a sério.” (entrevistada 9). 


\section{IV - DISFUNÇÕES E INADEQUAÇÕES SEXUAIS.}

Disfunções sexuais são caracterizadas pelo mau funcionamento da vida sexual de uma determinada pessoa ou no ajuste enquanto casal, numa ótica mais voltada para o mecanismo da resposta sexual fisiológica e a inadequação sexual é no sentido psicológico, pelo histórico pessoal de vivências, de se adequar ou não, constituindo um conceito relacional.

“[...] Eu não faço questão de sexo, eu preferia que não existisse, no início até era bom [...] eu gostaria de ter algo na minha mente que definisse o que eu sinto, mas eu realmente não sei definir [...] Acho que ele é impaciente, apressado, aí ele se chateia, mas também não fala, não conversa, e quando a gente tem um relacionamento mais íntimo, eu tenho que dizer, é melhor assim, mas em seguida ele esquece o que agrada e o que não agrada.” (1)

A partir da dificuldade de ter orgasmo e da dispareunia - disfunção - foi gerando uma inadequação; a falta de concepção da sexualidade de uma forma natural por parte da entrevistada é percebida pelo discurso vinculado a crenças errôneas. Desmotivada, a pessoa em questão adapta-se com a ausência de sensação, pois esta não lhe traduz significado ou, se um dia traduziu sentido, provavelmente foi negativo e com tentativas frustradas, bloqueado.

“[...] Não acontece muitas vezes da gente ter uma relação, acho que mais por minha culpa, no início porque ela (filha) era muito pequena, tem que dar atenção, a gente nem tem vontade, e depois porque eu mesma, sempre tive pouca vontade. Ele tem mais, e quer que eu tenha, mas nem ele, às vezes, me procura, aí ele espera que eu queira.” (3). “[...] Depois que veio a nossa filha a relação é cada vez mais rara... O porquê? Não sei, a gente não sente, sexo não é tão necessário, e tem umas barreiras... Às vezes ela acha que eu passo do ponto demais, já chegou a lubrificação e quando vou fazer a penetração, já está seca, ou eu passo do ponto, ou não chego no ponto, eu tenho que ir na sorte [...] E ÀS VEZES EU SINTO FALTA DE UM CARINHO DELA TAMBÉM!" (4).

Segundo Buber (1974), o verdadeiro diálogo consiste em um encontro entre um EU e um TU. Desse modo, o que predomina é a presença do EU-ISSO, que é marcada pela ausência da intimidade e de envolvimento.

“[...] A gente conversa muito, às vezes eu não sei como ajudar, ela sempre foi meio presa na relação, depois que nasceu nossa filha, a coisa esfriou, não sei se é pela mudança, ela está mais envolvida com a nenê, com a casa, e eu, 
passo o dia fora, aí chego em casa, não é que eu não queira ajudar, ela acaba fazendo melhor." (10).

A construção sociocultural no contexto do casal acima, reflete as diferenças de gênero, mediada pela cultura, nesta perspectiva sobressai-se o papel de mãe, inerente à própria condição de mulher. Em contrapartida, os homens, muitas vezes, sentem dificuldades em incorporar a sexualidade como expressão do ser em todos os momentos de sua vida . Ocorre resignação com relação às modificações de sua vida sexual e surgem outros sentimentos e responsabilidades, incompatíveis com a qualidade sexual. O erotismo masculino tem, em geral, uma estrutura temporal descontínua, fragmentada, ao contrário da mulher, cujo erotismo é nutrido por uma continuidade amorosa.

\section{Considerações finais}

A busca inicial que motivou a realização deste trabalho foi amplamente superada, porque a metodologia qualitativa fenomenológica e os princípios filosóficos de um pensamento sistêmico readaptou a pesquisa num recuo estratégico, saber da disfunção era pouco, o "saber" em questão agora, era o que se passava na "alma” dos casais quando eles tinham seu primeiro filho, com um olhar voltado para a sexualidade. A vida sexual após o parto não deve ser negada, ela existe, pode ser insólita, escassa ou enriquecedora, antes de saber como ela está, com a pesquisa foi possível compreender o que significa.

A essência do trabalho, através das falas dos entrevistados, está na ressignificação do sexo, do vínculo de casal e retomada após o parto; onde o "sexo" foi um meio de promover a compreensão externa, enquanto casal. E num segundo ponto, revelaram-se vivências e reestruturação da identidade, que tinham a ver com uma reorganização interna do indivíduo. Esses passos puderam mostrar um caminho traçado pelos entrevistados e, diante das dificuldades, sinalizar a morbidade de uma possível disfunção ou inadequação sexual, permitindo a elaboração de um atendimento preventivo.

Horizonte 1. Elaboração de um atendimento preventivo: A elaboração de atendimento preventivo, multidisciplinar, tem como fundamento esta idéia de que há um processo de transformação, o qual envolve a sexualidade no pós-parto, e ser um facilitador deste processo, promovendo o acolhimento 
e reestruturação, o que nos diferencia do ponto de vista profissional, de meros técnicos a profissionais abertos e receptivos, simplesmente, mais humanos.

Horizonte 2. O entendimento da vida sexual após o parto: Frankl (1991) refere que os aspectos transitórios na vida são as potencialidades, porém, quando realizadas, transformam-se em realidades; ficam a salvo e resguardadas da transitoriedade. É um recurso inigualável no entendimento do que é "ser sexual", temos um potencial, se tentarmos abreviar as dificuldades, resta-nos o não vivido, mas temos a responsabilidade de viver o amor em sua plenitude, e se de alguma forma tivermos sofrido, ainda assim teremos uma história de vida real, para sempre. Assumir a responsabilidade sexual é tomar postura frente à vida, concretizando a própria existência. Os casais citados neste trabalho, satisfeitos sexualmente, conseguem transcender-se no outro. Têm um entendimento real da cumplicidade sexual e não buscam o prazer pessoal como prioridade. A pessoa que ama capacita a pessoa amada a realizar estas potencialidades. $\mathrm{O}$ amor é um fenômeno tão primário como o sexo, e este é uma modalidade de expressão desta experiência (FRANKL, 1991).

Na busca de um significado de transformação da vida sexual de casais que passam pela experiência de ter um filho, encontrei o sentido de renovação na experimentação de dar sentido à própria vida, à do outro (o parceiro) e à do filho (causa); podendo ser o sexo vivido com esse amor, o instrumento para resgatar essa oportunidade.

Horizonte 3. A coletividade na intrínseca familiar: $\mathrm{O}$ substrato filosófico humanístico facilita o entendimento do indivíduo como um todo; é arte antes de técnica, e esta é mero instrumento de adequação. A vivência e a prática de estar com o outro conduzem à transformação, silencioso internamente no outro, podemos resgatar um processo evolutivo de sua capacidade individual. O centrar-se na técnica é um enfoque para o coletivo, que tem um valor genérico; mas é um meio, não uma finalidade. "Cada pessoa é um milagre suficiente para não ter de se comparar, a não ser consigo mesmo" (TORO apud CREMA, 1985); tratar o homem de forma coletiva suprime sua singularidade. A maior arte é entender que a saúde coletiva é um meio de se chegar à essência do indivíduo.

Ao término deste trabalho, ouso chamar de "intrínseca familiar" a força interna gerada a partir da unidade "família", primitiva e constante forma de agregação; capaz de ressignificar entendimentos e transmitir valores, e dentro destes o sexo vivido de forma saudável e responsável; assim, teremos a projeção disto para o todo (a humanidade); é a coletividade da intrínseca familiar, resgatando o poder de transformar comportamento. 


\section{Referências bibliográficas}

BUBER, M. Eu e Tu. São Paulo: Oraes, 1974.

CARIDADE, A. Sexualidade: corpo e metáfora. São Paulo: Iglu,1997.

CAVALCANTI, R. A História Natural do Amor. São Paulo: Gente, 1995.

CAVALCANTI, R.C. Sexualidade e Gestação. In: SALES, J.M.; VITIELLO, N.; CONCEIÇÃO, I.S.; CANELLA. P.R.B. Tratado de Assistência PréNatal. São Paulo: Roca, 1989.

Tratamento Clínico das Inadequações Sexuais. 2.ed. São Paulo: Roca, 1996.

COMIOTTO, M.S. Adultos Médios: Sentimentos e Trajetória de Vida. Um estudo Fenomenológico e Propostas de Auto-Educação. Tese (Doutorado em Ciências Humanas: Educação) Universidade Federal do Rio Grande do Sul, 1992.

CREMA, R. Análise Transacional Centrada na Pessoa. São Paulo: Ágora, 1985. FOUCAULT, M. História da Sexualidade. Rio de Janeiro: Graal, 1982. FRANKL, V.E. Em Busca de Sentido. Rio de Janeiro: Vozes, 1991.

GIORGI, A. Phenomenology and Psycological Research. Pittsburgh: Duquesne University Press, 1985.

HEIDEGGER, M. Ser e Tempo. Trad. de Márcia de Sá Cavalcanti. Petrópolis: Vozes, 1988.

HENNEMANN, M. S. Fenomenologia e psicologia em Amadeu Giorgi. Seminário sobre pesquisa Fenomenológica nas Ciências Humanas e Sociais. Anais, ANPESS/CBC/SS, 1990.

HUDSON, O.P. Reescrevendo histórias de amor. Terapia breve para casais.

Trad. Maria Carbajal e Magda Lopes. Campinas: ed. Pys II, 1995.

HUSSERL, E. A Idéia da Fenomenologia. Lisboa: Ediçōes 70, 1986.

JACOBS, J.; WOLIN, G. Ritual strengthering. Family Therapy Networker. 13:3, 41. jul-ago, 1989.

KAPLAN, H. S. Transtornos do Desejo Sexual. Regulação Disfuncional da Motivação Sexual. Trad. Jussara Burnier. Porto Alegre: Artes Médicas, 1999. KARMENN, P. Psycological. Reports, 76 (3, pt1): 831-834, Jun, 1995. MARTINS, J.; BICUDO, M.A.V. Estudos sobre Existencialismo, Fenomenologia e Educação. São Paulo: Moraes, 1989.

MASSIL, H. Post partum Sexual Function: What is the norm? Sexual-andMarital-Therapy, 10 (3): 263-276, Nov, 1995.

MERLEAU-PONTY, M. Fenomenologia de la Percepción. Barcelona: Península, 1975.

MONEY, J. Love Maps. New York: Irvington, 1986.

MORENO, J.L. Psicoterapia de grupo e Psicodrama. São Paulo: Mestre Jou, 1974. 
VITIELLO, N. Aspectos sistêmicos da sexualidade. Bol. Sbrash, 3:26, 1989. . Vida sexual após o parto. Comunicação pessoal. 05/2000,

ZILLES, U. Edmund Hussel e a Fenomenologia. Veritas, Porto Alegre, v.31, n.122, p.173-194, jun, 1986.

\section{Bibliografia consultada}

BARTHES, R. Fragmentos de um discurso amoroso. Rio de Janeiro: Francisco Alves, 1991.

BYRD, J. E.; HYDE, J. S.; DELAMATER, J. D.; PLANT, E. Ashby. Sexuality During Pregnancy and Year Post partum. The journal of Family Practice. 47 (4) pp.305-8, oct, 1998.

CAPRA, F. O Ponto de Mutação. São Paulo: Cultrix, 1991.

FONSECA, J. Psicoterapia da Relação. São Paulo: Ágora, 2000.

FREITAS, F. e cols. (org.) Rotinas em Obstetrícia. 3.ed. Porto Alegre: Artes Médicas, 1997.

HYDE, J.S.; KLEIN, M.H.; ESSEX, M.J.; CLARK, R. Maternity Leave and Women's Mental Health. Psycol Women A, 19: 257-85 [ Psyc. INFO Link], 1995.

MAIA, A.C.B. Sexualidade na Gravidez e Após o Parto. Revista Bras. Sexualidade Humana, 12(1): 15-25, 2001.

MASTERS, W.H.; JOHNSON, V.E. Human Sexual Inadequacy. Little Brown, 1970.

PEREIRA, V.M.A. Gravidez e Sexualidade: a vivência de mitos e tabus. Relatos de homens e mulheres. Revista Bras. Sexualidade Humana, 12(1) p. 83-105, 2001.

RAPHAEL - LEFF, J. Gravidez: a história interior. Trad. Rui D. Pereira. Porto Alegre: Artes Médicas, 1997.

SOIFER, R. Psicologia da gravidez, parto e puerpério. Trad. Jeka Valle de Carvalho. Porto Alegre: Artes Médicas, 1980. 